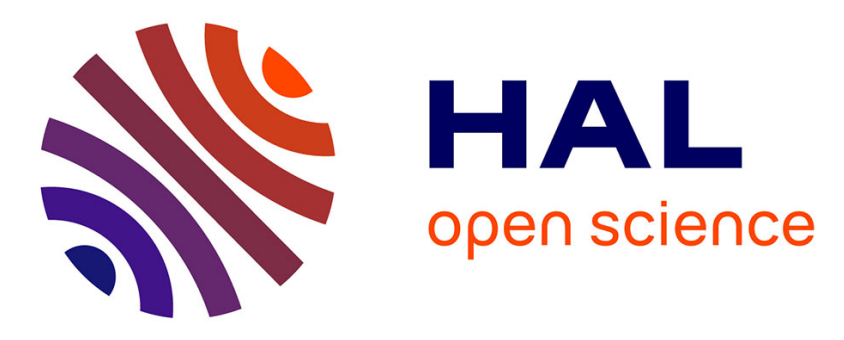

\title{
Photoinduced Formation of H-bonded Ion Pair in HCFC-133a
}

Gessenildo Pereira Rodrigues, Thayana Maria Lopes de Lima, Railton Barbosa de Andrade, Gessenildo Pereira Rodrigues, Thayana Maria Lopes de Lima, Railton Barbosa de Andrade, Elizete Ventura, Silmar Andrade Do Monte, Mario Barbatti

\section{To cite this version:}

Gessenildo Pereira Rodrigues, Thayana Maria Lopes de Lima, Railton Barbosa de Andrade, Gessenildo Pereira Rodrigues, Thayana Maria Lopes de Lima, et al.. Photoinduced Formation of Hbonded Ion Pair in HCFC-133a. Journal of Physical Chemistry A, 2019, 123 (10), pp.1953-1961. 10.1021/acs.jpca.8b12482 . hal-02288785

\section{HAL Id: hal-02288785 \\ https://hal-amu.archives-ouvertes.fr/hal-02288785}

Submitted on 19 Sep 2019

HAL is a multi-disciplinary open access archive for the deposit and dissemination of scientific research documents, whether they are published or not. The documents may come from teaching and research institutions in France or abroad, or from public or private research centers.
L'archive ouverte pluridisciplinaire HAL, est destinée au dépôt et à la diffusion de documents scientifiques de niveau recherche, publiés ou non, émanant des établissements d'enseignement et de recherche français ou étrangers, des laboratoires publics ou privés. 


\title{
Photoinduced Formation of H-bonded Ion Pair in HCFC-133a
}

Gessenildo Pereira Rodrigues ${ }^{1,2}$, Thayana Maria Lopes de Lima ${ }^{1}$, Railton Barbosa de Andrade ${ }^{1}$, Elizete Ventura ${ }^{1}$, Silmar Andrade do Monte ${ }^{1 *}$, Mario Barbatti ${ }^{3 *}$

${ }^{1}$ Universidade Federal da Paraíba, 58059-900, João Pessoa-PB, Brazil.

${ }^{2}$ Faculdade Rebouças, 58406-040, Campina Grande-PB, Brazil.

${ }^{3}$ Aix Marseille Univ, CNRS, ICR, Marseille, France.

\begin{abstract}
High-level multireference electronic structure calculations have been performed to study the $\mathrm{Cl}^{-}$yield from photoexcited $\mathrm{CF}_{3} \mathrm{CH}_{2} \mathrm{Cl}$ (HCFC-133a). The analysis of this process tells that it relates to an electron transfer from the carbon to the $\mathrm{Cl}$ atom, forming a highly polar contact ion-pair complex, $\mathrm{CF}_{3} \mathrm{HCH}^{+} \cdots \mathrm{Cl}^{-}$, in the excited $\left(\mathrm{S}_{3}\right)$ state. This complex has a strong binding energy of $3.53 \mathrm{eV}$, from which $0.47 \mathrm{eV}$ is due to an underlying hydrogen bond. Through comparison with the results obtained for the prototype $\mathrm{CH}_{3} \mathrm{Cl}$ system, where a similar ion-pair state associated with $\mathrm{Cl}^{-}$formation has also been observed, it is suggested that photodissociation of HCFC-133a can also yield $\mathrm{Cl}^{-}$through analogous process. This hypothesis is further supported by nonadiabatic dynamics simulations, which shows formation of the ion-pair complex in the subpicosecond time scale.
\end{abstract}




\section{Introduction}

Compared to chlorofluorocarbons (CFCs), hydrochlorofluorocarbons (HCFCs) are much less harmful to the ozone layer, mainly due to their degradation by reactions with $\mathrm{OH}$ radicals in the troposphere. ${ }^{1}$ Nevertheless, as the HCFCs are important greenhouse-effect gases, ${ }^{2}$ they have been included in the Kyoto protocol, ${ }^{3}$ which aims to stop their production until 2020. ${ }^{4-8} \mathrm{HCFC}-133 \mathrm{a}\left(\mathrm{CF}_{3} \mathrm{CH}_{2} \mathrm{Cl}\right)$ has been used in the pharmaceutical industry and also as a precursor of the HFC-134a $\left(\mathrm{CF}_{3} \mathrm{CH}_{2} \mathrm{~F}\right){ }^{9,}{ }^{90}$ It was first detected in the atmosphere four years ago, by Laube et. al. ${ }^{11}$ More recently, McGillen et. $a l{ }^{12}$ have evaluated several parameters of HCFC-133a with important atmospheric implications.

Ground state reactions of HCFC-133a have been studied by several authors. Three thermal reaction channels, induced using the infrared multiphoton absorption technique, have been studied by Setser et. al., ${ }^{13}$ and Rakestraw and Holmes ${ }^{14}$ measured the rate constants for these three reactions. Enstice et. al. ${ }^{15}$ studied HCFC-133a formation from $\mathrm{CF}_{2} \mathrm{ClCH}_{2} \mathrm{~F}^{*}$ molecules, while Wang et. al. ${ }^{16}$ and Zhao et. al. ${ }^{17}$ have studied its hydrogen abstraction reactions by $\mathrm{F}$ and $\mathrm{Cl}$ atoms, respectively, through direct dynamics calculations. More recently, McGillen et. $a l .{ }^{12}$ have studied the rate coefficient of its reaction with $\mathrm{OH}$.

On the other hand, studies concerning its photochemical reactions are much scarcer. To the best of our knowledge, there is only one experimental study involving primary photochemical processes for the HCFC-133a molecule. ${ }^{18}$ Two wavelengths (at 123.6 and $147 \mathrm{~nm}$ ) have been used, and molecular as well as halogen elimination have been observed. ${ }^{18}$ The quantum yields of molecular processes increase with photon energy, due to the preferential formation of a Rydberg state. ${ }^{18}$ Our group performed the first excited-state calculations for the vertical excitation of HCFC-133a, at the MR-CISD level in the range up to $9.8 \mathrm{eV} .{ }^{19}$ Later, our group performed nonadiabatic dynamics calculations at the TDDFT level starting at the $10 \pm 0.25 \mathrm{eV}$ spectral window, ${ }^{20}$ to compare to the experimental results obtained by Ichimura et. al. after $123.6 \mathrm{~nm}$ excitation. ${ }^{18}$ The main experimental channel, $\mathrm{Cl}+\mathrm{F}$ elimination, should preferentially take place through $\mathrm{Cl}$ dissociation in the excited state followed by $\mathrm{F}$ dissociation in the ground state, while the second main experimental channel $(\mathrm{Cl}+\mathrm{H})$ are mainly due to excited-state fragmentation. ${ }^{20}$ While the third channel $(\mathrm{F}+\mathrm{H})$ should have a partial 
contribution from ground-state fragmentation. $\mathrm{CC}$ bond fission are expected to take place exclusively in the excited state, followed by recombination in the ground state. ${ }^{20}$

Now, we focus on the elimination of $\mathrm{Cl}^{-}$anion from HCFC-133a. The experimental data from ref. ${ }^{18}$ does not make clear how much of the $\mathrm{Cl}$ elimination is due to such charged species. Nevertheless, in the closely related system $\mathrm{CH}_{3} \mathrm{Cl} \mathrm{Cl}^{-}$is the dominant anion formed, and its most intense peak is in the region from 10.5 to $11.9 \mathrm{eV}$, as revealed by the vacuum-UV photoexcitation (in the range from 8 to $35 \mathrm{eV}$ ) investigations by Tuckett et al. ${ }^{21,22}$ In particular, due to the linear dependence of its signal with pressure, the authors concluded that $\mathrm{Cl}^{-}$(and the other anions studied) arises from ion-pair formation instead of from dissociative electron attachment. ${ }^{21,} 22$ Recently, our group characterized ${ }^{23}$ the photochemical formation of such a transient $\mathrm{H}$-bonded ion pair for the $\mathrm{CH}_{3} \mathrm{Cl}$, with a structure represented by $\mathrm{H}_{2} \mathrm{CH}^{+} \ldots \mathrm{Cl}^{-}$, during the predissociation of $\mathrm{Cl}^{-}$(reaction (1)). Due to the substantial similarity between the electronic properties of $\mathrm{CF}_{3} \mathrm{CH}_{2} \mathrm{Cl}$ and $\mathrm{CH}_{3} \mathrm{Cl}$ (these similarities are discussed later in this work), it is likely that $\mathrm{Cl}^{-}$fragments are yielded from HCFC-133a through an ion-pair state analogous to that of $\mathrm{CH}_{3} \mathrm{Cl}$ (reaction (2)).

$$
\begin{gathered}
\mathrm{CH}_{3} \mathrm{Cl} \stackrel{h v}{\rightarrow}\left[\mathrm{H}_{2} \mathrm{CH}^{+} \ldots \mathrm{Cl}^{-}\right]^{*} \rightarrow \mathrm{H}_{2} \mathrm{CH}^{+}+\mathrm{Cl}^{-} \\
\mathrm{CF}_{3} \mathrm{CH}_{2} \mathrm{Cl} \stackrel{h v}{\rightarrow}\left[\mathrm{CF}_{3} \mathrm{HCH}^{+} \ldots \mathrm{Cl}^{-}\right]^{*} \rightarrow \mathrm{CF}_{3} \mathrm{CH}_{2}^{+}+\mathrm{Cl}^{-}
\end{gathered}
$$

In the present work, multireference configuration interactions with singles and doubles plus size-extensivity corrections (MR-CISD+Q) is used to map fourteen excited states of $\mathrm{CF}_{3} \mathrm{CH}_{2} \mathrm{Cl}$, including valence and Rydberg states. Emphasis is given to nonadiabatic relaxation pathways along the $\mathrm{C}-\mathrm{Cl}$ coordinate, which can lead to an ionpair whose structure is like that found for $\mathrm{CH}_{3} \mathrm{Cl}$. The same types of excited states involved in the ion-pair formation of $\mathrm{CH}_{3} \mathrm{Cl}$ are obtained here. The properties of the $\mathrm{CF}_{3} \mathrm{HCH}^{+} \ldots \mathrm{Cl}^{-}$ion pair are discussed in detail and compared to those of the $\mathrm{H}_{2} \mathrm{CH}^{+} \ldots \mathrm{Cl}^{-}$ ion-pair.

To check the hypothesis that the population of the $\mathrm{CF}_{3} \mathrm{HCH}^{+} \ldots \mathrm{Cl}^{-}$ion pair state could be a primary source of $\mathrm{Cl}^{-}$fragments, on-the-fly non-adiabatic mixed quantumclassical dynamics, ${ }^{24}$ starting from the $\sigma 4 p_{\sigma}$ state, is also performed. The choice of this state arises from comparison with $\mathrm{CH}_{3} \mathrm{Cl}$, for which, among all computed states in ref. ${ }^{23}$, the $\sigma 3 p_{\sigma}$ state is the one which is expected to lead to the ion-pair channel with maximum 
probability. Due to the exceedingly high computational costs of such simulations, they are not affordable at the MR-CISD levels employed in the discussion of the potential energy curves. Although they could have been done at MCSCF level with some smaller basis set, the lack of electron dynamic correlation would have led to unreliable results. Therefore, for the dynamics simulations, we resorted to an entirely distinct electronicstructure methodology, the linear-response time-dependent density functional theory (TDDFT).

The results from the potential energy mapping and dynamics simulations led to a picture where the high-energy excitation of HCFC-133a triggers a cascade of nonadiabatic events, which significantly populate an ion-pair state and yield $\mathrm{Cl}^{-}$ fragments.

\section{Computational details}

First, the ground state geometry of HCFC-133a has been optimized at the MP2 level with the aug-cc-pVTZ basis set. ${ }^{25}$ Then, a relaxed scan along the $\mathrm{C}-\mathrm{Cl}$ coordinated has been performed at the same level, from 1.766 to $\sim 3.6 \AA$. At the obtained structures, single-point calculations at the multiconfigurational self-consistent field (MCSCF) and MR-CISD levels have then been done to map the fifteen lowest singlet states. $C_{s}$ symmetry has been used for the potential energy profiles. Previous calculations performed for the $\mathrm{CF}_{3} \mathrm{Cl}$ molecule indicate that the spin-orbit couplings for this type of molecule is small, about $0.009 \mathrm{eV} .{ }^{26}$ Therefore, as our focus is the ultrafast (subpicosecond) relaxation, we restricted the investigations to the singlet manifold.

The symmetry plane is the xy plane. The initial molecular orientation is shown in Figure 1. The $\mathrm{Cl}$ atom $3 \mathrm{p}$ lone pair along the $\mathrm{C}-\mathrm{Cl}$ axis is named $3 \mathrm{p}_{\sigma}$, and its interaction with the singly occupied $2 \mathrm{p}_{\sigma}(\mathrm{C})$ orbital of the $\mathrm{CF}_{3} \mathrm{CH}_{2}$ radical leads to the bonding and anti-bonding $\sigma$ and $\sigma^{*}$ orbitals. The symmetric and anti-symmetric $\mathrm{Cl}$ lone pairs are designated as $\mathrm{n}_{1}$ and $\mathrm{n}_{2}$, respectively. The set of $\mathrm{ns}, \mathrm{np} \mathrm{p}_{\sigma}$, and the $\left(\mathrm{np}_{1}, \mathrm{np}_{2}\right)$ pair of Rydberg orbitals have also been included. All These orbitals are shown in Table S4 of the Supporting Information. 


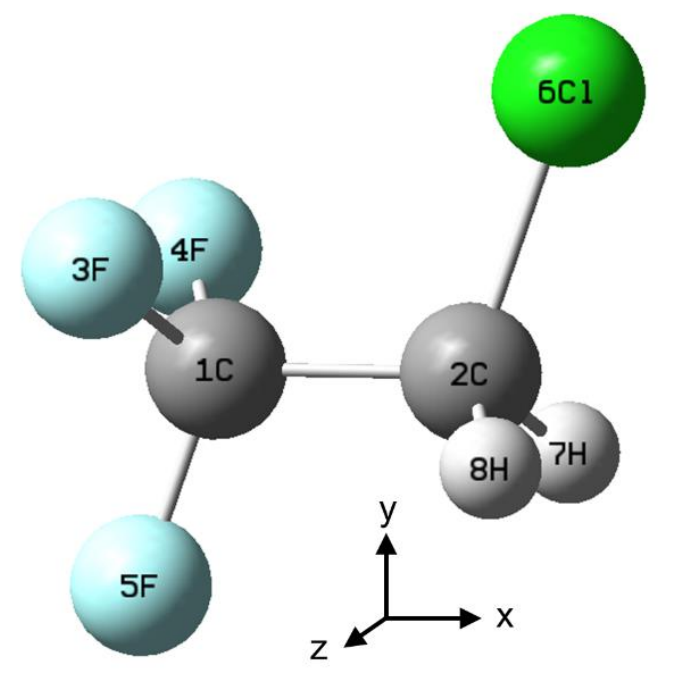

Figure 1. Initial molecular orientation used for the calculation of the vertical states and also as the starting point for generating the relaxed geometries used for the subsequent potential energy curves calculations.

For the single-point calculations, the refl space defined in Table 1 has been used at the MCSCF and MR-CISD levels. The complete active space (CAS) at the MCSCF level has been chosen to comprise 6 electrons (four from the two $\mathrm{n}$ orbitals and two from the $\sigma$ bond). The $\sigma^{*}$ orbital has also been included in the CAS, while the four Rydberg orbitals (ns, $\mathrm{np}_{\sigma}$, and the $\left(\mathrm{np}_{1}, \mathrm{np}_{2}\right)$ pair) have been added to the auxiliary (AUX) space, with the restriction that only single CAS $\rightarrow$ AUX excitations are allowed. Fifteen $\left(9 \mathrm{~A}^{\prime}\right.$ and $\left.6 \mathrm{~A}^{\prime \prime}\right)$ singlet states with equal weights have been included in the state-averaged MCSCF calculations.

Table 1. Active and reference spaces used for the species studied in this manuscript. When it is the case, only CAS $\rightarrow$ AUX excitations have been employed.

\begin{tabular}{|l|c|c|c|c|}
\hline \multirow{2}{*}{ Reference space } & \multicolumn{2}{|c|}{ MCSCF } & \multicolumn{2}{c|}{ MR-CISD } \\
\cline { 2 - 5 } & CAS & AUX & CAS & AUX \\
\hline valence & $\mathrm{n}_{1}, \mathrm{n}_{2}, \sigma, \sigma^{*}$ & ---- & $\mathrm{n}_{1}, \mathrm{n}_{2}, \sigma, \sigma^{*}$ & --- \\
\hline ref1 & $\mathrm{n}_{1}, \mathrm{n}_{2}, \sigma, \sigma^{*}$ & $\mathrm{~ns}, \mathrm{np}_{\sigma}, \mathrm{np}_{1}, \mathrm{np}_{2}$ & $\mathrm{n}_{1}, \mathrm{n}_{2}, \sigma, \sigma^{*}$ & $\mathrm{~ns}, \mathrm{np}_{\sigma}, \mathrm{np}_{1}, \mathrm{np}_{2}$ \\
\hline
\end{tabular}

Full geometry optimizations have been performed for the $3^{1} \mathrm{~A}^{\prime}$ (the ion-pair) state, at the MR-CISD level, using the valence space at both MR-CISD and MCSCF 
levels (see Table 1). The absence of Rydberg orbitals, in this case, is justified by the significant energy difference between the ion-pair and the next high-lying state (an n3s Rydberg, see Figure 2). For the valence space, four $\left(3 \mathrm{~A}^{\prime}\right.$ and $\left.1 \mathrm{~A}^{\prime \prime}\right)$ singlet states with equal weights have been included in the state-averaged MCSCF calculations.

At the MR-CISD level, the low-lying orbitals at the ground state geometry are divided into two subsets, that is, the frozen-core (FC) and the valence orbitals. The former set includes the $\mathrm{K}$ (for the $\mathrm{C}$ and $\mathrm{F}$ atoms) and $\mathrm{K}+\mathrm{L}$ (for the $\mathrm{Cl}$ atom) shells, while the second set consists of the doubly occupied valence orbitals. Previous calculations on similar systems indicate that the $\mathrm{L}$ shell of the $\mathrm{Cl}$ atom has virtually negligible importance on the excited states' properties. ${ }^{26,27}$ The doubly occupied orbitals remain with fixed (that is, equals two) occupation numbers only in the reference configurations, while the FC orbitals remain doubly occupied in the reference as well as in the excited CSF space.

The reference configuration state functions (CSF) are then used to generate the excited CSF space through single and double excitations from all internal (active + doubly occupied) into all virtual orbitals, at the MR-CISD level. The final CSF space comprises the reference and the excited CSFs. In generating this last MR-CISD expansion, the interactive space restriction has been used. ${ }^{28}$ The Davidson correction extended to the multi-reference case $(+Q)$ has been used to account for the size-extensivity error. ${ }^{29,} 30$

The purpose of choosing refl space is to get a correct description of the fifteen studied states in the region of the potential energy curves only up to a $\mathrm{C}-\mathrm{Cl}$ distance compatible with the formation of the ion-pair, 3.6 $\mathrm{\AA}$. A description of these states until complete dissociation requires the inclusion of additional states and orbitals. ${ }^{23,31}$ On the other hand, the valence space is adequate for a correct description of the ion-pair and its lower-lying states, $1^{1} \mathrm{~A}^{\prime}, 2^{1} \mathrm{~A}^{\prime}$ and $1^{1} \mathrm{~A}^{\prime \prime}$, from $~ 2.6 \AA$ to its complete dissociation.

The cation fragment $\left[\mathrm{CF}_{3} \mathrm{CH}_{2}\right]^{+}$, necessary to obtain the dissociation limit of the ion-pair channel, has been treated using an active space (at both CASSCF and MR-CISD levels) consisting of five orbitals, that is, the three lone pair orbitals of the $\mathrm{F}$ atom in the symmetry plane, along with the $2 \mathrm{p}_{\sigma}$ orbitals of both $\mathrm{C}$ atoms. This choice is due to the $\mathrm{F}$ migration, from $\mathrm{C} 1$ to $\mathrm{C} 2$, observed at correlated levels. ${ }^{32}$ These orbitals are shown in Table S5 of the Supporting Information. Three (2A' and $\left.1 \mathrm{~A}^{\prime \prime}\right)$ singlet states with equal weights have been included in the state-averaged CASSCF calculations. After geometry optimization of the $\left[\mathrm{CF}_{3} \mathrm{CH}_{2}\right]^{+}$fragment, the $\mathrm{Cl}$ atom was placed at a distance of $50 \AA$ 
from the charge-center (the $\mathrm{C} 1$ atom, as the final optimized structure is $\left[\mathrm{CF}_{2} \mathrm{CFH}_{2}\right]^{+}$due to $\mathrm{F}$ migration) and collinear with both $\mathrm{C}$ atoms. This supermolecule has then been used to obtain the dissociation limit of the ion-pair channel (with the valence space). The residual Coulomb energy between the charged species $(0.29 \mathrm{eV}$ at $50 \AA)$ was further discounted from the potential energy of the supermolecule.

The aug-cc-pVTZ basis set ${ }^{25}$ has been used at the MP2 level, while the MR-CISD potential energy curves have been computed with the mixed d-aug-cc-pVTZ(Cl)/aug-cc$\mathrm{pVDZ}(\mathrm{C}, \mathrm{H}, \mathrm{F})$ basis set (named B1 from here on). This basis set has been shown to be flexible enough to handle localization of the Rydberg orbitals either in the $\mathrm{Cl}$ or in the $\mathrm{C} 2$ atom, a necessary requisite, as such localization changes with the $\mathrm{C}-\mathrm{Cl}$ distance. Geometry optimizations of the $\left[\mathrm{CF}_{3} \mathrm{CH}_{2}\right]^{+}$fragment in the ground and ion-pair states have been performed with the mixed aug-cc-pVDZ $(\mathrm{C}, \mathrm{F}) / \mathrm{cc}-\mathrm{pVTZ}(\mathrm{H}, \mathrm{Cl})$ basis set $(\mathrm{B} 2$ basis set). Single-point calculations on the supermolecule in the ground and ion-pair state geometries have been performed with the mixed aug-cc-pVTZ $(\mathrm{C}, \mathrm{H}, \mathrm{Cl}) / \mathrm{cc}-\mathrm{pVTZ}(\mathrm{F})$ basis set (B3 basis set). Details on the basis set choice are discussed in the Supporting Information (SI-7).

Nonadiabatic dynamics simulations were carried out to address the possibility of reaching the ionic channel from the $\sigma 4 p_{\sigma}$ state. These simulations were performed as explained in ref. $^{20}$, that is, using decoherence-corrected fewest-switches surface hopping ${ }^{33,34}$ at the TDDFT level ${ }^{31,35}$ with the $\omega \mathrm{B} 97 \mathrm{XD}$ functional. ${ }^{36}$ The only difference is that in the present work a spectral window at $11.2 \pm 0.25 \mathrm{eV}$ has been chosen for the initial excitation, which corresponds to a window centered at the vertical excitation energy of the $\sigma 4 p_{\sigma}$ state, obtained at the TDDFT/ $\omega$ B97XD level with the d-aug-cc$\mathrm{pVDZ}(\mathrm{Cl}) /$ aug-cc-pVDZ(H,C,F) basis set (B4 basis set). One hundred initial conditions were stochastically sampled in this window according to their excitation probabilities. As explained in ref..$^{20}$, the trajectories ran for a maximum time of $1000 \mathrm{fs}$ or until they reach an $\mathrm{S}_{1} / \mathrm{S}_{0}$ energy gap smaller than $0.1 \mathrm{eV}$. The latter condition due to limitations of the linear-response TDDFT to deal with $\mathrm{S}_{1} / \mathrm{S}_{0}$ degeneracies. ${ }^{37}$

All geometry optimizations at the MR-CISD level have been performed through analytical gradient techniques. ${ }^{38-41}$ All MP2 calculations have been performed with the GAUSSIAN 09 software, ${ }^{42}$ while all MCSCF, MR-CISD, and MR-CISD+Q calculations have been done with the COLUMBUS program system. ${ }^{43-46}$ The DALTON program ${ }^{47}$ has been used to compute the atomic orbitals (AO) integrals as well as the AO gradient 
integrals used by COLUMBUS. The non-adiabatic dynamics calculations were performed using NEWTON-X ${ }^{48,49}$ interfaced with GAUSSIAN 09. ${ }^{42}$

\section{Results and Discussion}

\subsection{Vertical Excitation}

In Table 2, the vertical excitation energies, oscillator strengths $(f)$, and the spatial extension of the CI wavefunction $\left(\left\langle\mathrm{r}^{2}\right\rangle\right)$, as well as the CI weights of the main configurations are given. Comparison with previous results, obtained with the B1 basis set, is also provided.

Table 2. Vertical excitation energies ( $\Delta E_{\mathrm{v}}$, in $\mathrm{eV}$, at the MR-CISD+Q level), spatial extension $\left(\left\langle\mathrm{r}^{2}\right\rangle\right)$, and oscillator strengths $(f)$ for $\mathrm{CF}_{3} \mathrm{CH}_{2} \mathrm{Cl}$ obtained at the MR-CISD/refl level with the $\mathrm{B} 1$ basis set.

\begin{tabular}{|c|c|c|c|c|c|}
\hline \multirow{2}{*}{ State } & \multicolumn{2}{|c|}{$\Delta E_{v}(\mathrm{eV})$} & \multirow{2}{*}{$f$} & \multirow{2}{*}{$<\mathbf{r}^{2}>\left(\mathrm{a}_{0}^{2}\right)$} & \multirow{2}{*}{ Main configuration } \\
\hline & $\mathrm{CI}+\mathrm{Q}$ & $\mathrm{CI}+\mathrm{Q}^{\mathrm{b}, \mathrm{c}}$ & & & \\
\hline $1{ }^{1} \mathrm{~A}^{\prime}$ & 0.00 & 0.00 & - & 88.32 & $0.81($ closed shell) \\
\hline $2^{1} \mathrm{~A}^{\prime}$ & 7.91 & 7.97 & 0.001 & 105.63 & $0.60 n_{1} \sigma^{*+0.22 n_{1} 4 p_{\sigma}}$ \\
\hline $3^{1} \mathrm{~A}^{\prime}$ & 8.45 & 8.41 & 0.04855 & 132.37 & $0.80 \mathrm{n}_{1} 4 \mathrm{~s}$ \\
\hline $4^{1} \mathrm{~A}^{\prime}$ & 9.23 & 9.19 & 0.01434 & 150.18 & $0.83 \mathrm{n}_{2} 4 \mathrm{p}_{2}$ \\
\hline $5^{1} \mathrm{~A}^{\prime}$ & 9.56 & 9.53 & 0.01331 & 154.42 & $0.61 n_{1} 4 p_{1}+0.14 n_{1} 4 p_{\sigma}$ \\
\hline $6^{1} \mathrm{~A}^{\prime}$ & 9.82 & 9.80 & 0.02443 & 159.14 & $0.47 n_{1} 4 p_{\sigma}+0.19 n_{1} 4 p_{1}+0.15 n_{1} \sigma^{*}$ \\
\hline $7^{1} \mathrm{~A}^{\prime}$ & 11.65 & --- & 0.007107 & 131.74 & $0.80 \sigma 4 \mathrm{~s}$ \\
\hline $8^{1} \mathrm{~A}^{\prime}$ & 12.07 & --- & 0.36092 & 149.58 & $0.66 \sigma 4 p_{\sigma}+0.13 \sigma \sigma^{*}$ \\
\hline $9^{1} \mathrm{~A}^{\prime}$ & 12.82 & -- & 0.01575 & 165.67 & $0.80 \sigma 4 \mathrm{p}_{1}$ \\
\hline $1^{1} \mathrm{~A}^{\prime \prime}$ & 7.81 & 7.86 & 0.0006 & 105.60 & $0.55 n_{2} \sigma^{*}+0.23 n_{2} 4 p_{\sigma}$ \\
\hline $2^{1} \mathrm{~A}^{\prime \prime}$ & 8.33 & 8.29 & 0.03311 & 131.54 & $0.76 \mathrm{n}_{2} 4 \mathrm{~s}$ \\
\hline $3^{1} \mathrm{~A}^{\prime \prime}$ & 9.33 & 9.31 & 0.00094 & 150.36 & $0.81 \mathrm{n}_{1} 4 \mathrm{p}_{2}$ \\
\hline $4^{1} \mathrm{~A}^{\prime \prime}$ & 9.49 & 9.45 & 0.01671 & 155.95 & $0.69 n_{2} 4 p_{1}$ \\
\hline $5^{1} \mathrm{~A}^{\prime \prime}$ & 9.67 & 9.65 & 0.008831 & 158.76 & $0.47 n_{2} 4 p_{\sigma}+0.19 n_{2} \sigma^{*}$ \\
\hline $6^{1} \mathrm{~A}^{\prime \prime}$ & 12.47 & --- & 0.021108 & 151.05 & $0.84 \sigma 4 \mathrm{p}_{2}$ \\
\hline
\end{tabular}

${ }^{a}$ Ground-state energies: -796.790689 (MR-CISD); -796.931224 (MR-CISD+Q); ${ }^{\text {bFrom ref. }}{ }^{19}$; ${ }^{\mathrm{c}}$ With the B4 basis set.

As can be seen from Table 2, there is an excellent agreement between the current results and those from ref. ${ }^{19}$, with a maximum difference of only $0.05 \mathrm{eV}$. The primary weights are maintained, as can be seen through comparison between Table 1 and Table IV from ref. ${ }^{19}$. However, the results with the smaller basis set, B4, show a slightly larger 
multiconfigurational character for some states. The energy differences between the $\mathrm{A}^{\prime}$ and $\mathrm{A}^{\prime \prime}$ states arising from the same configuration (and involving excitation from the $\mathrm{n}$ orbitals) are in the range from 0.07 to $0.15 \mathrm{eV}$, and are compatible with the difference of $0.09 \mathrm{eV}$ between the ionization potentials of the $\mathrm{n}_{1}$ and $\mathrm{n}_{2}$ lone pairs computed at the ROCCSD(T)/CBS level. ${ }^{50}$

As can also be seen from Table 2, the $\left\langle\mathrm{r}^{2}\right\rangle$ values lead to a clear separation between the valence $\left(105 \mathrm{a}_{0}^{2}\right)$ and Rydberg $\left(132-159 \mathrm{a}_{0}^{2}\right)$ states, although the $\left\langle\mathrm{r}^{2}\right\rangle$ values for the $n \sigma^{*}$ states are significantly larger than that of the ground state $\left(88 \mathrm{a}^{2}\right)$, due to a reasonable admixture with the $n 4 p_{\sigma}$ configuration.

The studied states of both $\mathrm{CF}_{3} \mathrm{CH}_{2} \mathrm{Cl}$ and $\mathrm{CH}_{3} \mathrm{Cl}$ molecules are qualitatively analogous, as they have the same nature and energy ordering. Unsurprisingly, the quantitative variations are indeed not small due to the difference between the $\mathrm{C}-\mathrm{H}$ and $\mathrm{C}-\mathrm{CF}_{3}$ bonds. For instance, the first two ionization potentials of the $\mathrm{CF}_{3} \mathrm{CH}_{2} \mathrm{Cl}$ molecule (both corresponding to ionization of $\mathrm{Cl}$ lone pairs) are 0.7 and $0.79 \mathrm{eV}$ larger than those of the $\mathrm{CH}_{3} \mathrm{Cl}$ molecule. ${ }^{50,51}$ The magnitude of such variation can also be seen in the differences between the excitation energies of these two molecules (both computed with the $\mathrm{B} 1$ basis set), as they can be as large as $0.85 \mathrm{eV}$ (for the $\sigma 4 \mathrm{p}$ state), with the HCFC133a molecule yielding larger values.

One central point of the present study is to demonstrate that, despite the quantitative variations mentioned, the similarities between $\mathrm{CH}_{3} \mathrm{Cl}$ and $\mathrm{CF}_{3} \mathrm{CH}_{2} \mathrm{Cl}$ are strong enough so that one can expect a similar behavior for the latter based on what is observed for the former. Thus, some shared features by both molecules are: (i) the largest $f$ value has been obtained for an $\mathrm{n}-k \mathrm{p}_{\sigma}$ state (with $k=3$ for the $\mathrm{CH}_{3} \mathrm{Cl}^{23}$ and $k=4$ for $\mathrm{CF}_{3} \mathrm{CH}_{2} \mathrm{Cl}$ ), followed by an $n-k$ s state (cf. Table 2 with Table 1 from ref. ${ }^{23}$ ); (ii) the vertical excitation energy into the $n-k p_{\sigma}$ state is very close to the vertical ionization potential; (iii) the potential energy curves along the $\mathrm{C}-\mathrm{Cl}$ coordinate have similar topography; (iv) both molecules form the same type of ion pair, that is, a hydrogen-bonded contact ion pair. The points (iii) and (iv) will be discussed in sections 3.2 and 3.3, respectively.

\subsection{Potential energy curves}

In Figure 2, the potential energy curves along the $\mathrm{C}-\mathrm{Cl}$ coordinate (relaxed scan in $\mathrm{S}_{0}$ ) are shown. These curves share the following features with those from $\mathrm{CH}_{3} \mathrm{Cl}^{23}$ (i) 
they have the same crossings or avoided crossings between the $n 4 p$ and $\sigma 4 \mathrm{~s} / \sigma 4 \mathrm{p}$ states; (ii) after $\sim 2.3 \AA$, the ionic configuration shows up in the $3^{1} \mathrm{~A}^{\prime}$ state, and its weight increases until it becomes dominant from $\sim 3.0 \AA$ on (in the case of $\mathrm{CH}_{3} \mathrm{Cl}$, the corresponding state is $2^{1} \mathrm{~A}_{1}$ ); (iii) around $3.2 \AA$, one has a partial minimum for the $3^{1} \mathrm{~A}^{\prime}$ state, suggesting that it can become an actual minimum. In Figures S1 to S3 of the Supporting Information, the avoided crossings within the sets of $\mathrm{A}^{\prime}$ and $\mathrm{A}^{\prime \prime}$ states are shown.

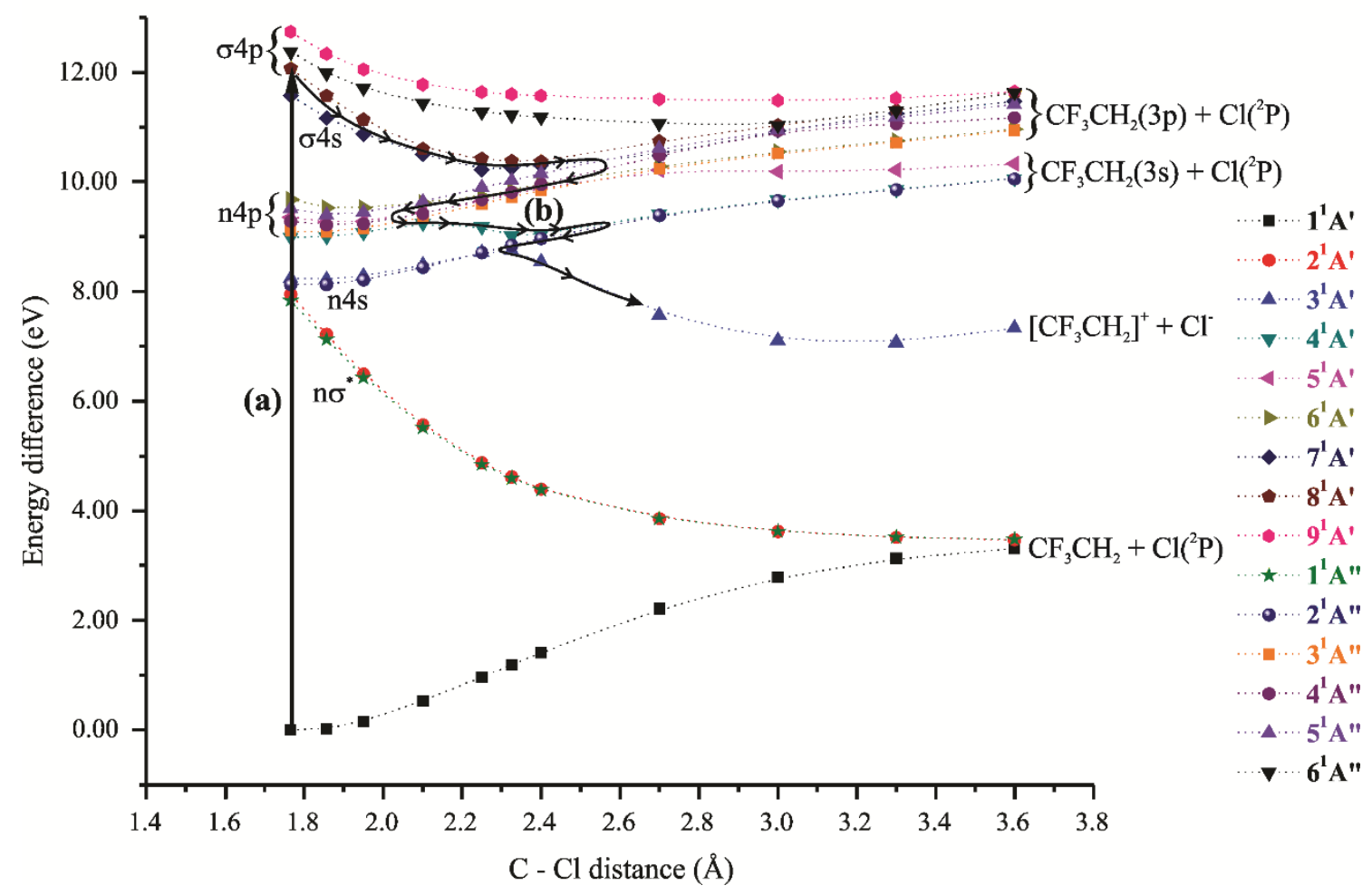

Figure 2. Potential energy curves for the $\mathrm{C}-\mathrm{Cl}$ coordinate (relaxed scan in $\mathrm{S}_{0}$ ) of the $\mathrm{CF}_{3} \mathrm{CH}_{2} \mathrm{Cl}$ molecule, computed at the MR-CISD/refl level with the B1 basis set. The bold line indicates a possible pathway to relax to the ion-pair state, triggered by a vertical excitation into the state with the largest $f$ value (the $8^{1} \mathrm{~A}^{\prime}$ state).

The bold line in Figure 2 shows a possible pathway to relax into the ion-pair state, starting from the $8^{1} \mathrm{~A}^{\prime}$ state, the one to which a vertical transition from the ground state has the largest $f$ value (see Table 2). Such pathway can be induced by elongations and shortenings of the $\mathrm{C}-\mathrm{Cl}$ bond and it consists of several nonadiabatic transitions, which can take place either maintaining or breaking the symmetry plane, depending on the pair of states involved. The first transition is from the $8^{1} \mathrm{~A}^{\prime}$ to the $7^{1} \mathrm{~A}^{\prime}$ state, which occurs at 
$\sim 2.0 \AA$ upon loss of the symmetry plane. The $\mathrm{C}-\mathrm{Cl}$ bond elongation can proceed until $2.55 \AA$, where the energy differences between the $7^{1} \mathrm{~A}^{\prime}$ and the $\mathrm{n} 4 \mathrm{p}$ states can decrease, inducing $7^{1} \mathrm{~A}^{\prime} \rightarrow \mathrm{n} 4 \mathrm{p}$ transitions. A subsequent shortening of the $\mathrm{C}-\mathrm{Cl}$ bond until $\sim 2.05$ $\AA$ can be accompanied by an energy decrease and by an approximation between $n 4 p$ states, inducing a cascade of transitions until the lowest $n 4 p$ state $\left(4^{1} \mathrm{~A}^{\prime}\right)$ is reached. Then, from this state, a further elongation of the $\mathrm{C}-\mathrm{Cl}$ bond can decrease its energy and lead to a quasi-degeneracy between the $4^{1} \mathrm{~A}^{\prime}$ and $2^{1} \mathrm{~A}^{\prime \prime}$ states. Finally, a further shortening can bring the $2^{1} \mathrm{~A}^{\prime \prime}$ and $3^{1} \mathrm{~A}^{\prime}$ states near, inducing the final $2^{1} \mathrm{~A}^{\prime \prime} \rightarrow 3^{1} \mathrm{~A}^{\prime}$ transition. Once the $3{ }^{1} \mathrm{~A}^{\prime}$ state is reached, an elongation of the $\mathrm{C}-\mathrm{Cl}$ bond stabilizes it (see Figure 2). This sequence of events is a simplified picture of the nonadiabatic transitions required to bring the system to the ion-pair state. A more detailed analysis of the time evolution of some geometrical parameters will be given in section 3.4.

\subsection{Characterization of the hydrogen-bonded $\mathrm{CF}_{3} \mathrm{HCH}^{+} \mathrm{Cl}^{-}$ion pair}

The relaxed scan shown in Figure 2 suggests the occurrence of a minimum for a $\mathrm{C}-\mathrm{Cl}$ bond distance of $\sim 3 \AA$ for the $3^{1} \mathrm{~A}^{\prime}$ state. Thus, the corresponding structure resulting from this scan has been used as the initial guess for full geometry optimization of this state at the MR-CISD/valence level (see Table 1) with the B2 basis set. Although such calculation has been performed without symmetry, the obtained structure (shown in Figure 3(a)) virtually has $\mathrm{C}_{\mathrm{s}}$ symmetry. Its normal mode analysis yields an imaginary frequency mode that breaks the $\mathrm{C}_{\mathrm{s}}$ symmetry and decreases the $\angle_{\mathrm{CHCl}}$ bond angle (that is, the $\mathrm{Cl}$ atom tends to become collinear with the $\mathrm{C}-\mathrm{H}$ bond). After following this mode and performing a new geometry optimization, the structure shown in Figure 3(b) is obtained. The Cartesian coordinates of both structures are given in the Supporting Information, SI3. 
(a)

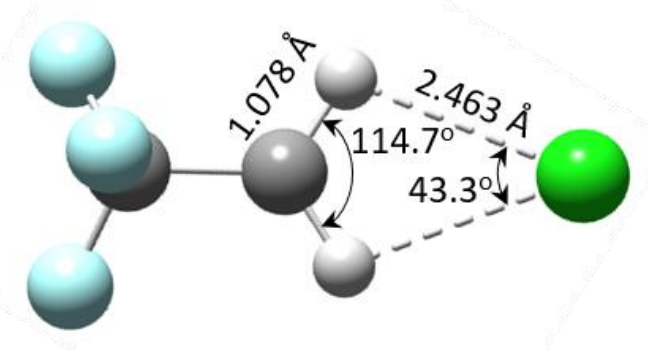

(b)

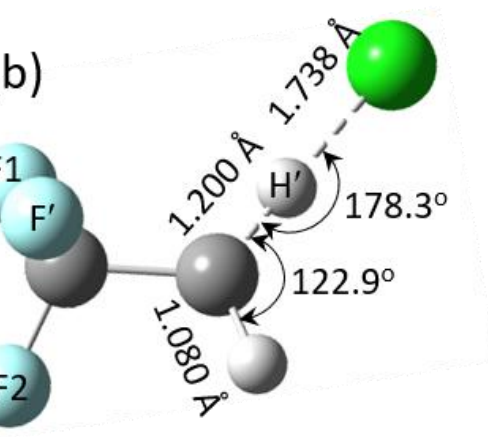

Figure 3. (a) Transition state resulting from the geometry optimization of the $3^{1} \mathrm{~A}^{\prime}$ state based on the relaxed scan shown in Figure 2; (b) Structure of the hydrogen-bonded ion pair obtained for the $3^{1} \mathrm{~A}^{\prime}$ state of the $\mathrm{CF}_{3} \mathrm{CH}_{2} \mathrm{Cl}$ molecule, computed at the MR$\mathrm{CISD} /$ valence level with the $\mathrm{B} 2$ basis set. The main geometrical parameters are shown in the plot. $\mathrm{F} 1$ and $\mathrm{F} 2$ refer to the $\mathrm{F}$ atoms that are closer to the $\mathrm{CCH}^{\prime}$ and $\mathrm{CCH}$ planes, respectively.

A comparison between the $\mathrm{C} \cdots \cdot \mathrm{H}$ and $\mathrm{H} \cdots \mathrm{Cl}$ bond distances (along with the $\angle_{\mathrm{CHCl}}$ bond angle, fragment charges, dipole moment and binding energy) computed for the $\mathrm{CF}_{3} \mathrm{CH}_{2} \mathrm{Cl}$ and the $\mathrm{CH}_{3} \mathrm{Cl}$ molecules indicates similar hydrogen bonds. The $\mathrm{C} \cdots \cdot \mathrm{H}$ bond distance of the $\mathrm{CF}_{3} \mathrm{HCH}^{+} \ldots \mathrm{Cl}^{-}$ion pair is larger than that of the $\mathrm{H}_{2} \mathrm{C}^{+} \mathrm{H}^{\prime} \cdots \mathrm{Cl}^{-}$ion pair by $0.042 \AA$. In turn, the $\mathrm{H} \cdots \mathrm{Cl}$ bond distance is smaller by $0.144 \AA$.

The charge separation in the $\left[\mathrm{CF}_{3} \mathrm{CH}_{2}\right]^{+\delta} \mathrm{Cl}^{-\delta}$ ion pair, $\delta=0.93$, is slightly larger than that in the ion $\left[\mathrm{CH}_{3}\right]^{+\delta} \mathrm{Cl}^{-\delta}$ pair, $\delta=0.90$. The corresponding dipole moments are similar too, with values of 9.44 and $10.26 \mathrm{D}$, respectively. All these values have been obtained from single-point calculations (at the MR-CISD/valence level with the B3 basis set) performed on the optimized geometries. The binding energies of the $\mathrm{CF}_{3} \mathrm{HCH}^{+} \ldots \mathrm{Cl}^{-}$ and $\mathrm{H}_{2} \mathrm{CH}^{+} . . \mathrm{Cl}^{-}$ion pairs are 4.30 and $3.53 \mathrm{eV}$, respectively, with the same basis at the MR-CISD+Q level. The difference of $0.77 \mathrm{eV}$ between these two values can be partially explained by the inequivalent dissociated structures used as a reference to compute the binding energy. While $\mathrm{CH}_{3} \mathrm{Cl}$ simply dissociates into $\mathrm{CH}_{3}{ }^{+}+\mathrm{Cl}^{-}$in the ionic channel, in the same channel, dissociated HCFC-133a is further stabilized by an F migration, $\mathrm{CF}_{3} \mathrm{C}^{+} \mathrm{H}_{2} \rightarrow \mathrm{C}^{+} \mathrm{F}_{2} \mathrm{CFH}_{2}$. Consequently, the energy of the ionic channel decreases, leading to smaller binding energy for the bonded ion pair. The $\mathrm{F}$ migration of $\mathrm{CF}_{3} \mathrm{C}^{+} \mathrm{H}_{2}$ cation has 
been previously characterized at the MP2 level. ${ }^{32}$ Additional calculations at other correlated levels, along with previous results at the HF level, indicate that such spontaneous migration can only be captured at post-Hartree-Fock levels. The computed value of $10.78 \mathrm{eV}$ for the vertical ionization potential (at the MP2/aug-cc-pVTZ level) is in excellent agreement with the experimental value of $10.6 \mathrm{eV}$ given by Fisher et. al. ${ }^{52}$

The $\mathrm{C}^{+}-\mathrm{H}^{-\cdots \mathrm{Cl}^{-}}$moiety is a relatively uncommon structure. It has been reported in systems where the $\mathrm{C}$ atom is part of a heteroaromatic ring, and they are observed in the ground state. ${ }^{53}$ In the most common systems, the $\mathrm{C}$ atom is part of an imidazolium ring, and the ion pairs are essential units of ionic liquids. ${ }^{53-60}$ Due to the resonance structures, the positive charge center in these systems is shared between the $\mathrm{C}$ and two adjacent $\mathrm{N}$ atoms. ${ }^{57}$ To the best of our knowledge, the hydrogen-bonded contact ion pair given in ref. ${ }^{23}, \mathrm{H}_{2} \mathrm{CH}^{+} \ldots \mathrm{Cl}^{-}$, has been so far the only example of a molecule containing a $\mathrm{C}^{+}-\mathrm{H}^{\cdots} \mathrm{Cl}^{-}$ moiety in which the positive charge center $\left(\mathrm{C}^{+}\right)$is part of an aliphatic backbone. The $\mathrm{CF}_{3} \mathrm{CH}_{2} \mathrm{Cl}$ molecule adds to this group as it shares the same two characteristics (presence of the $\mathrm{C}^{+}-\mathrm{H} \cdots \mathrm{Cl}^{-}$moiety and the positive charge center, $\mathrm{C}^{+}$, as a part of an aliphatic backbone). For both $\mathrm{CF}_{3} \mathrm{CH}_{2} \mathrm{Cl}$ and $\mathrm{CH}_{3} \mathrm{Cl}$, however, the ion pairs are formed in the excited state.

The binding energy of $3.53 \mathrm{eV}$ obtained here is close to the value of $4.07 \mathrm{eV}$ obtained at the MP2 level for the hydrogen-bonded 1-ethyl-3-methylimidazolium chloride (EMIC) ion pair. ${ }^{56}$ The same holds for the $\mathrm{C}-\mathrm{Cl}$ distances obtained for both systems, which differ by just $0.087 \AA$, although for the latter, the $\mathrm{H}^{\prime} \mathrm{Cl}$ distance is longer by $\sim 0.162 \AA .{ }^{56}$ Compared to the value of $3.53 \mathrm{eV}$ obtained for the $\mathrm{CF}_{3} \mathrm{HCH}^{+} \ldots \mathrm{Cl}^{-}$ion pair, the value of $4.07 \mathrm{eV}$ for the EMIC ion pair is closer to the amount of $4.30 \mathrm{eV}$ for the $\mathrm{H}_{2} \mathrm{CH}^{+} \ldots \mathrm{Cl}^{-}$ion pair. Such agreement can be explained by the absence of atom migration in this case, which reinforces the hypothesis that the F migration is essential for the destabilization of the $\mathrm{CF}_{3} \mathrm{HCH}^{+} \ldots \mathrm{Cl}^{-}$ion pair.

In Table 3, the computed vibrational frequencies of the hydrogen-bonded contact ion-pair, $\mathrm{CF}_{3} \mathrm{HCH}^{+} \ldots \mathrm{Cl}^{-}$(structure (b) in Figure 3), are given. As the normal coordinates differ significantly from those of the $\left[\mathrm{H}_{2} \mathrm{C}^{+} \mathrm{H}\right] \mathrm{Cl}^{-}$ion pair as well as from those of the ground state of the $\mathrm{CF}_{3} \mathrm{CH}_{2} \mathrm{Cl}$ molecule they cannot be directly compared. 
Table 3. Vibrational frequencies (in $\mathrm{cm}^{-1}$ ) for the $\mathrm{CF}_{3} \mathrm{HCH}^{+} . . \mathrm{Cl}^{-}$hydrogen-bonded contact ion pair, obtained at the MR-CISD/valence level with the B2 basis set. For the atoms' labeling see Figure 3(b).

\begin{tabular}{|c|c|}
\hline$v\left(\mathrm{~cm}^{-1}\right)$ & Approximate description \\
\hline 35.4 & $\mathrm{CH}^{\prime} \mathrm{Cl}$ out-of-plane bending ${ }^{\mathrm{a}}$ coupled to $\mathrm{F} 1 \mathrm{CC}$ and $\mathrm{CCH}$ bending \\
\hline 71.9 & $\mathrm{C}-\mathrm{H}^{\prime}$ stretching coupled to $\mathrm{H}^{\prime} \mathrm{Cl}$ stretching and to $\mathrm{CFF}^{\prime}$ twisting \\
\hline 286.5 & $\mathrm{CH}^{\prime} \mathrm{Cl}$ out-of-plane bending ${ }^{\mathrm{a}}$ coupled to $\mathrm{F}^{\prime} \mathrm{CC}$ and $\mathrm{CCH}$ bending. \\
\hline 304.7 & $\begin{array}{l}\mathrm{CH}^{\prime} \mathrm{Cl} \text { out-of-plane bending }{ }^{\mathrm{a}} \text { coupled to } \mathrm{H}^{\prime} \mathrm{Cl} \text { and } \mathrm{CH} \text { stretching and to } \\
\mathrm{CF} 1 \mathrm{~F} 2 \text { twisting }\end{array}$ \\
\hline 470.9 & $\begin{array}{l}\text { symmetric } \mathrm{CH}_{2} \text { stretching coupled to } \mathrm{H}^{\prime} \mathrm{Cl} \text { stretching, to antisymmetric } \\
\mathrm{CF} 2 \mathrm{~F}^{\prime} \text { stretching and to } \mathrm{CF} 1 \mathrm{~F}^{\prime} \text { bending }\end{array}$ \\
\hline 540.0 & $\mathrm{CH}_{2}$ twisting coupled to $\mathrm{CF}_{2}$ antisymmetric stretching \\
\hline 558.1 & asymmetric $\mathrm{CH}_{2}$ stretching coupled to $\mathrm{H}^{\prime} \mathrm{Cl}$ stretching and $\mathrm{CF}_{1} \mathrm{~F}^{\prime}$ bending \\
\hline 619.1 & $\mathrm{CH}_{2}$ twisting coupled to $\mathrm{H}^{\prime} \mathrm{Cl}, \mathrm{C}-\mathrm{C}$ and $\mathrm{CF}^{\prime} \mathrm{F}^{\prime}$ symmetric stretching \\
\hline 766.9 & out-of-plane $\mathrm{CH}^{\prime} \mathrm{Cl}$ bending ${ }^{\mathrm{a}}$ \\
\hline 894.8 & $\begin{array}{l}\text { F1CCH rotation coupled to } \mathrm{CF} 1 \mathrm{~F}^{\prime} \text { twisting and bending and to } \mathrm{CH}^{\prime} \text { and } \\
\mathrm{H}^{\prime} \mathrm{Cl} \text { stretching }\end{array}$ \\
\hline 1010.7 & $\mathrm{H}^{\prime} \mathrm{Cl}$ stretching coupled to $\mathrm{CH}^{\prime}$ stretching and in-plane $\mathrm{CH}^{\prime} \mathrm{Cl}$ bending ${ }^{\mathrm{a}}$ \\
\hline 1227.0 & $\mathrm{CH}_{2}$ wagging \\
\hline 1336.8 & symmetric $\mathrm{CH}_{2}$ stretching coupled to $\mathrm{F}^{\prime} \mathrm{CC}$ twisting \\
\hline 1368.4 & $\mathrm{CH}^{\prime} \mathrm{Cl}$ (in phase) stretching coupled to $\mathrm{CCF}^{\prime}$ twisting \\
\hline 1500.9 & out-of-plane $\mathrm{CH}^{\prime} \mathrm{Cl}$ bending ${ }^{\mathrm{a}}$ \\
\hline 1531.7 & $\begin{array}{l}\mathrm{CH}^{\prime} \text { stretching anti-symmetrically (out-of-phase) coupled to } \mathrm{H}^{\prime} \mathrm{Cl} \text { stretching } \\
\text { and symmetrically coupled to } \mathrm{C}-\mathrm{C} \text { stretching and also coupled to nearly } \\
\text { in-plane } \mathrm{CH}^{\prime} \mathrm{Cl} \text { bending }\end{array}$ \\
\hline 1750.3 & $\begin{array}{l}\mathrm{CH}^{\prime} \text { stretching anti-symmetrically (out-of-phase) coupled to } \mathrm{H}^{\prime} \mathrm{Cl} \text { and } \mathrm{C}-\mathrm{C} \\
\text { stretching and also coupled to nearly in-plane } \mathrm{CH}^{\prime} \mathrm{Cl} \text { bending }\end{array}$ \\
\hline 3300.6 & in-plane $\mathrm{CH}^{\prime} \mathrm{Cl}$ bending $\mathrm{g}^{\mathrm{a}}$ coupled to $\mathrm{CH}^{\prime}$ and $\mathrm{H}^{\prime} \mathrm{Cl}$ stretching \\
\hline
\end{tabular}

aThe two different modes with the same description have the atomic displacements in opposite directions of the $\mathrm{CCH}$ plane (see also Table S3 of the Supporting Information). The plane used to define the in-plane and out-of-plane $\mathrm{CH}^{\prime} \mathrm{Cl}$ bending vibrations is the one defined by the $\mathrm{HCCl}$ atoms.

Although inclusion of the chloride anion increases the number of vibrational modes by three, the frequencies of the ion pair are better described regarding how the added anion modifies the cation frequencies. Nevertheless, the F migration prevents such comparison, as the formed $\mathrm{C}^{+} \mathrm{F}_{2} \mathrm{CFH}_{2}$ carbocation is not able to form any hydrogen bond with chloride. Still, the first two vibrational modes (in the far infrared region) are 
consistent with the corresponding modes observed in trialkyl ammonium salts. ${ }^{61}$ For these salts, the highest and the lowest frequencies (in the far infrared region) have been respectively assigned to the cation-anion stretching mode and to the $\mathrm{N}^{+}-\mathrm{H}^{-\cdots} \mathrm{Cl}^{-}$bending mode, which is consistent with the description given in Table 3 for the vibrational modes whose frequencies are 71.9 and $35.4 \mathrm{~cm}^{-1}$. The highest frequency $\mathrm{CH}^{\prime}$ stretching mode has a vibrational frequency of $1750.3 \mathrm{~cm}^{-1}$ (see Table 3 and Figure 3(b)), a value much smaller than the one obtained for the hydrogen-bonded 1-Butyl-3-methylimidazolium chloride, $2655 \mathrm{~cm}^{-1} .{ }^{57}$ This significant difference can be explained by the longer $\mathrm{CH}^{\prime}$ bond distance obtained here (1.200 versus $\left.1.111 \AA^{59}\right)$ and by its coupling with two lower frequency modes, that is, the $\mathrm{C}-\mathrm{C}$ stretching mode and the in-plane $\mathrm{CH}^{\prime} \mathrm{Cl}$ bending mode. "Pure" C-C stretching frequencies are observed at 800-1200 $\mathrm{cm}^{-1} .62$ Although a "pure" in-plane $\mathrm{CH}^{\prime} \mathrm{Cl}$ bending mode has not been obtained here, it is expected that its frequency is close to one of the two frequencies of the out-of-plane $\mathrm{CH}^{\prime} \mathrm{Cl}$ bending modes, observed at 766.9 and $1500.9 \mathrm{~cm}^{-1}$ (see Table 3). The relative displacement vectors for each normal mode are given in Table S3 of the Supporting Information.

\subsection{Nonadiabatic dynamics}

In the previous sections, we have argued that after a high-energy excitation of $\mathrm{CF}_{3} \mathrm{CH}_{2} \mathrm{Cl}$, a cascade of nonadiabatic events should produce $\mathrm{Cl}^{-}$fragments through the population of the ion-pair state. To verify this hypothesis, we have run on-the-fly nonadiabatic dynamics simulations.

As mentioned in the Introduction, the computational costs of those simulations at MR-CISD level are prohibitive. For this reason, we resorted to linear-response TDDFT, which can adequately describe the topography of the states of interest at a much lower cost. The critical point for such methodological shift is how well the TDDFT potential energies compare to those computed with MR-CISD.

In fact, we have already addressed this issue in ref. ${ }^{20}$, where we reported TDDFT dynamics for $\mathrm{CF}_{3} \mathrm{CH}_{2} \mathrm{Cl}$. The TDDFT calculations with the $\omega \mathrm{B} 97 \mathrm{XD}$ functional lead to a good description of the potential energy curves of the $\mathrm{CF}_{3} \mathrm{CH}_{2} \mathrm{Cl}$ molecule along the $\mathrm{C}-$ $\mathrm{Cl}$ coordinate, as can be seen through comparison between Figure (b) from Table S2 of ref. $^{20}$ and Figure 2. The main features correctly described at the TDDFT/ $\omega$ B97XD level are: (i) the separation between the groups of $n \sigma^{*}, \sigma 4 \mathrm{~s}$, and $\sigma 4 \mathrm{p}$ states in the region before 
$\sim 2.1 \AA$; (ii) the crossing between the $\mathrm{n} 4 \mathrm{~s}$ and the $3{ }^{1} \mathrm{~A}^{\prime}$ states upon $\mathrm{C}-\mathrm{Cl}$ elongation $\left(3^{1} \mathrm{~A}^{\prime}\right.$ becomes the ion-pair state upon elongation of the $\mathrm{C}-\mathrm{Cl}$ bond); (iii) the relatively close proximity between states $S_{4}$ to $S_{14}$ in the region between $\sim 2.6$ and $3.6 \AA$ ), within a relatively narrow range of $\sim 2.5 \mathrm{eV}$ (from $\sim 9.5$ to $12 \mathrm{eV}$ ). Although Figure (b) of Table $\mathrm{S} 2$ of ref. ${ }^{20}$ does not suggest the formation of a minimum in the fourth surface, after full geometry optimization of this state at the TDDFT/ $\omega$ B97XD level (with the B4 basis set) a minimum, whose structure is similar to that shown in Figure 3(b), is obtained. Its Cartesian coordinates are given in Table S2 of the Supporting Information.

In ref. ${ }^{20}$, the nonadiabatic dynamics calculations were performed exciting the molecule in a spectral window at $10.0 \pm 0.25 \mathrm{eV}$. A closer look at the results used to generate Table 3 of ref. ${ }^{20}$ indicates that 4 out of the 28 trajectories that yielded $\mathrm{Cl}$ fragments (from a total of 100 trajectories) ended up in the fourth surface $\left(\mathrm{S}_{3}\right)$, whose associated electronic configuration indicates the formation of the $\left[\mathrm{CF}_{3} \mathrm{CH}_{2}\right]^{+}$and $\mathrm{Cl}^{-}$ions. Therefore, considering the statistical uncertainty for a confidence interval of $95 \%$, the $\mathrm{Cl}^{-}$ yield is $4 \pm 3 \%$ at the $10.0 \pm 0.25 \mathrm{eV}$ excitation energy window.

There are four pieces of information that inspired us to run new nonadiabatic dynamics calculations for $\mathrm{CF}_{3} \mathrm{CH}_{2} \mathrm{Cl}$, but now using a spectral window at $11.2 \pm 0.25 \mathrm{eV}$ : (i) The $\mathrm{Cl}^{-}$generated from $\mathrm{CH}_{3} \mathrm{Cl}$ in the vacuum-UV photoexcitation experiments performed by Tuckett et al. ${ }^{21,22}$ has its largest yield in the range extending from $\sim 10.75$ to $11.75 \mathrm{eV}$. (ii) Results from ref. ${ }^{23}$ indicate that a $\sigma 3 \mathrm{p}_{\sigma}$ state is the state with the largest oscillator strength in this region. Besides, it is also the state with the largest oscillator strength among all computed states. ${ }^{23}$ (iii) For $\mathrm{CF}_{3} \mathrm{CH}_{2} \mathrm{Cl}$, the same type of state $\left(\sigma 4 \mathrm{p}_{\sigma}\right)$ is the one with the largest oscillator strength among all computed states, at both MR-

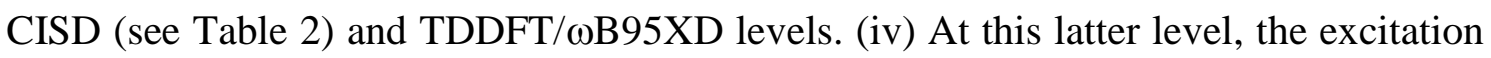
energy of the $\sigma 4 p_{\sigma}$ state is $11.2 \mathrm{eV}$. Therefore, we expected that nonadiabatic dynamics in a spectral window at $11.2 \pm 0.25 \mathrm{eV}$ should increase the $\mathrm{Cl}^{-}$yield, as compared to that performed at the $10.0 \pm 0.25 \mathrm{eV}$ spectral window. ${ }^{20}$

In fact, in the new set of dynamics simulations, fifteen out of 100 trajectories ended in the $\mathrm{S}_{3}$ ion-pair state, corresponding to a $\mathrm{Cl}^{-}$yield of $15 \pm 6 \%$ at the excitation energy window of $11.2 \pm 0.25 \mathrm{eV}$, an almost three times bigger yield than in the lower excitation window. ${ }^{20}$ In the following, we will focus the analysis exclusively on these fifteen trajectories yielding the ion pair. 
The time elapsed for the system to reach $S_{3}$ varies from 35 to 244 fs (mean value of $150 \mathrm{fs}$ with $70 \mathrm{fs}$ standard deviation), and once this surface is reached, the system remains on it until the end of the dynamics. Figure 4 shows a typical example. As explained in the Computational Details, for methodological reasons, trajectories were finished as soon as the $S_{0} / S_{1}$ energy gap became smaller than $0.1 \mathrm{eV}$, and this criterion was always satisfied within a time interval varying between 5 and 56.5 fs after reaching $S_{3}$. The occurrence of an $S_{1} / S_{0}$ degeneracy with the system still in $S_{3}$ is not surprising given the semi-dissociated configuration of the molecule.

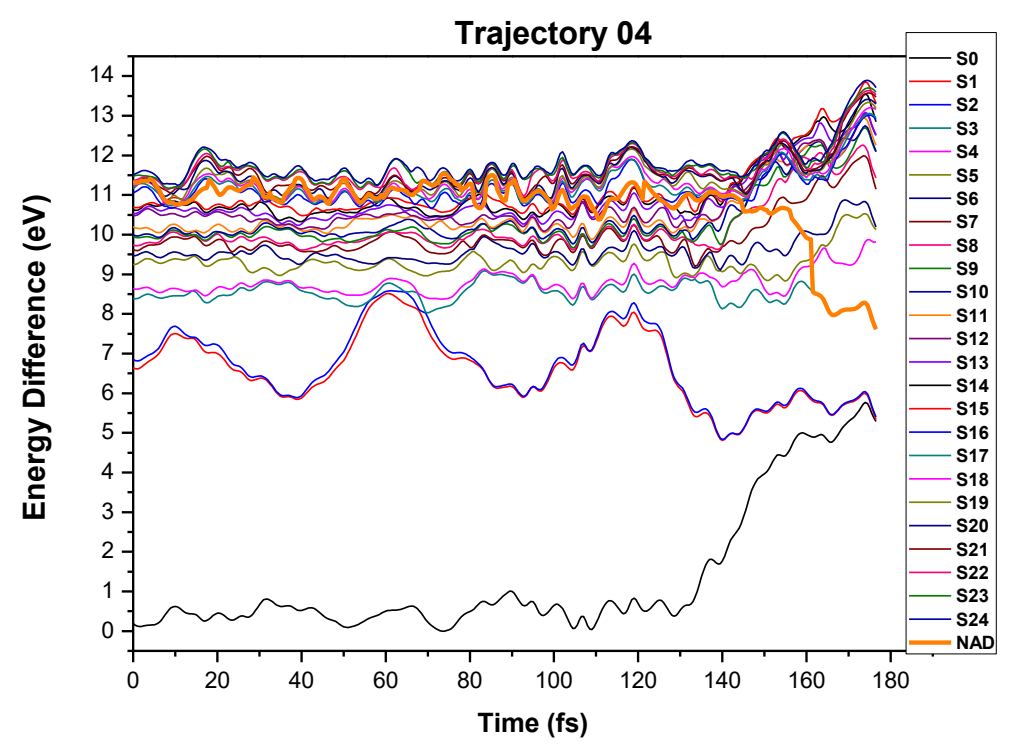

Figure 4. Time evolution of the potential energy surfaces for one of the fifteen trajectories that ended up in $\mathrm{S}_{3}$. NAD stands for the actual state where the system is at each time step.

Figure 5 shows the time evolution of the $\mathrm{C}-\mathrm{Cl}$ distance for the fifteen trajectories ending up in $\mathrm{S}_{3}$. As can be seen from this plot, $\mathrm{S}_{3}$ is always reached when the $\mathrm{C}-\mathrm{Cl}$ distance is larger than $2.0 \AA$. Besides, some oscillations are observed for most of the trajectories, which is in line with the simplified pathway shown in Figure 2. The trajectories hoped to $\mathrm{S}_{3}$ with an average $\mathrm{C}-\mathrm{Cl}$ distance of $2.61 \AA$ and with a standard deviation of $0.36 \AA$. 


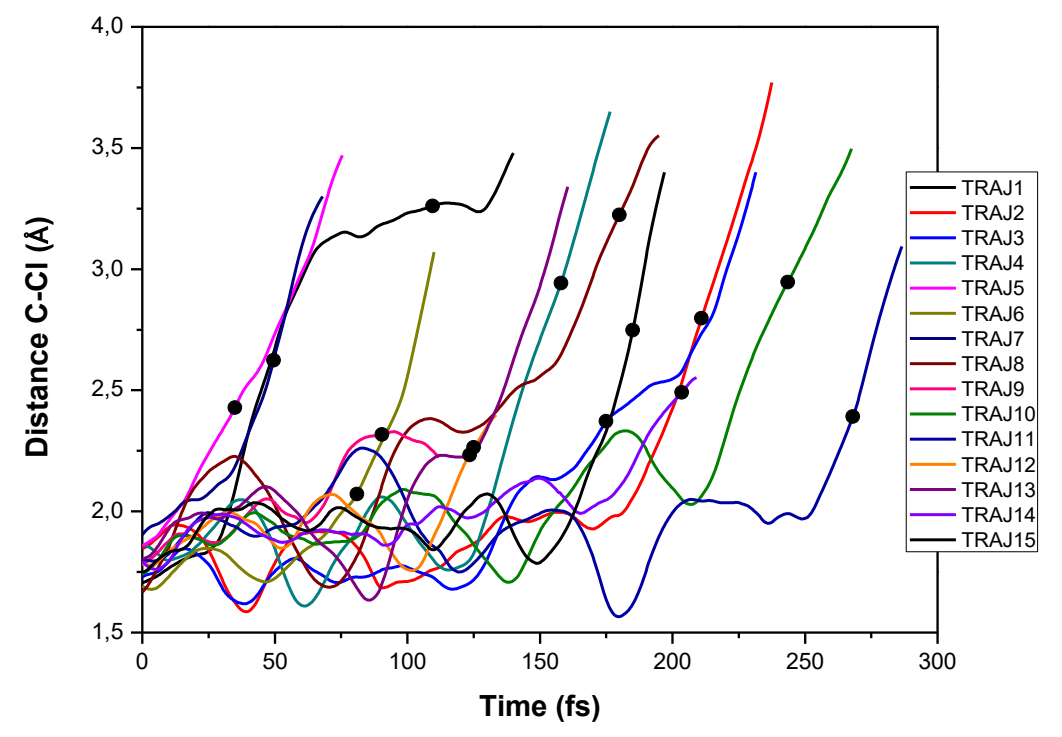

Figure 5. Time evolution of the $\mathrm{C}-\mathrm{Cl}$ distance for the fifteen trajectories which end up in $S_{3}$. The black circles indicate the time elapsed when $S_{3}$ is reached.

As shown in Figure 6, the 15 trajectories populating the ion-pair state reach $S_{3}$ near the symmetric structure (Figure 3(a)), although with a broad spread of $\mathrm{H}-\mathrm{Cl}$ distances, spanning from 2.5 to $3.5 \AA$. Due to the short period that they remain on $\mathrm{S}_{3}$ before reaching the termination criterion, it is not possible to observe the formation of the H-bond (in Figure 6, they would be represented by periodic motions around the (b) structures). Nevertheless, we see that most of the trajectories depart from the symmetric structure immediately after hopping to $S_{3}$, as expected. At this point it is not possible to tell whether following this evolution, the trajectories will quickly yield $\mathrm{Cl}^{-}$or stabilize in the ion-pair H-bond well. Given the considerable excess vibrational energy due to the nonadiabatic relaxation, the first option seems to be likely. 


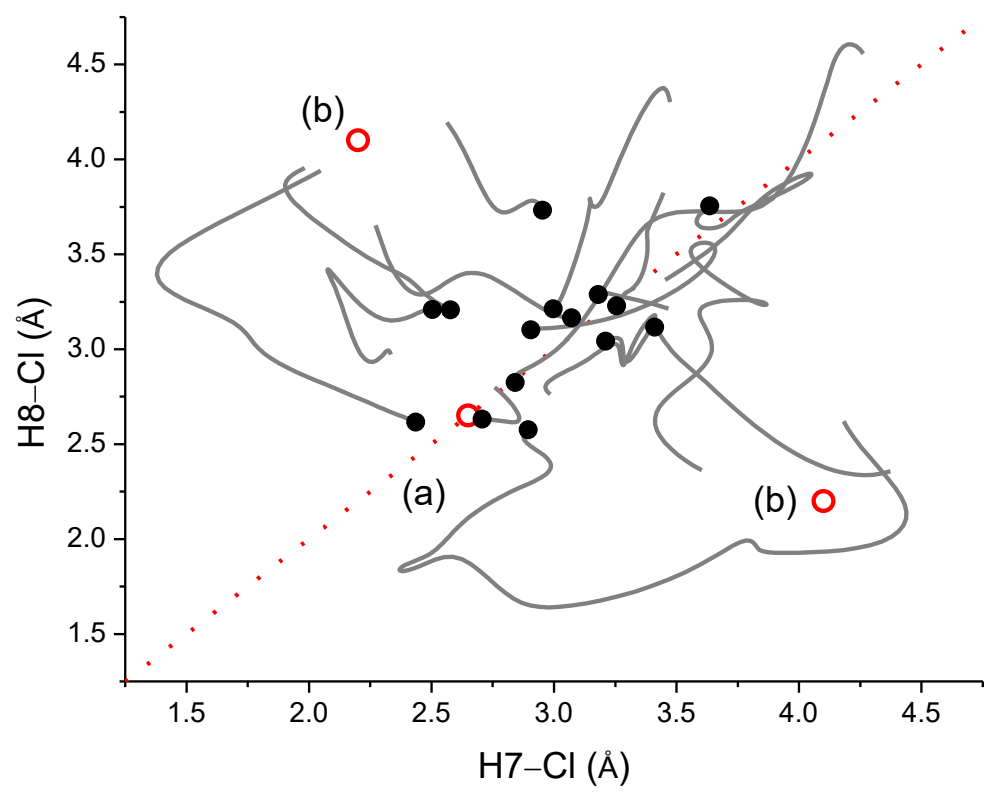

Figure 6. Time evolution of each the $\mathrm{H}-\mathrm{Cl}$ distance for each of the fifteen trajectories reaching the ion-pair state. The black dot indicates the time in which the trajectory hops to $S_{3}$. The open circles show the same types of ion pair structures shown in Figure 3(a) and Figure 3(b), but optimized with TDDFT.

\section{Conclusions}

The hydrogen-bonded contact ion pair of the $\mathrm{CF}_{3} \mathrm{CH}_{2} \mathrm{Cl}$ molecule has been studied at the highly correlated MR-CISD level, including extensivity corrections. Its structure can be represented by $\mathrm{CF}_{3} \mathrm{HCH}^{+} \ldots \mathrm{Cl}^{-}$. Our results indicate an extremely polar structure with a dipole moment of $10.26 \mathrm{D}$ and binding energy of $3.53 \mathrm{eV}$. This energy is $0.77 \mathrm{eV}$

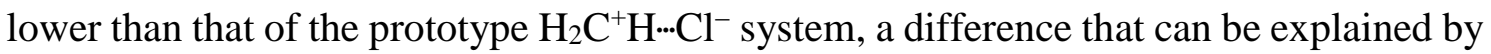
the additional stabilization of the $\mathrm{CF}_{3} \mathrm{C}^{+} \mathrm{H}_{2}$ carbocation due to the $\mathrm{F}$ migration, $\mathrm{CF}_{3} \mathrm{C}^{+} \mathrm{H}_{2}$ $\rightarrow \mathrm{C}^{+} \mathrm{F}_{2} \mathrm{CFH}_{2}$.

Potential energy curve calculations along the $\mathrm{C}-\mathrm{Cl}$ coordinate have also been performed to analyze the formation of the ion-pair state from the vertical excitation to the $\sigma 4 p_{\sigma}$ state, the one with the largest $f$ value. Such formation is based on several nonadiabatic transitions induced by $\mathrm{C}-\mathrm{Cl}$ elongations and shortenings.

Despite the stability of the $\mathrm{CF}_{3} \mathrm{HCH}^{+} \ldots \mathrm{Cl}^{-}$structure, it should have a short lifetime, as electronic to vibrational energy conversion during population transfer to the ion-pair state is likely to populate excited low-frequency vibrational levels, which can release $\mathrm{Cl}^{-}$ 
or $\mathrm{HCl}$. The detection of the $\mathrm{CF}_{3} \mathrm{HCH}^{+} \ldots \mathrm{Cl}^{-}$ion pair can be carried out through the same technique ${ }^{63}$ suggest to detect the related $\mathrm{H}_{2} \mathrm{CH}^{+} \ldots \mathrm{Cl}^{-}$ion pair. ${ }^{23}$

Nonadiabatic dynamics calculations at the TDDFT/ $\omega$ B97XD level along with the potential energy profiles computed at the MR-CISD level suggest the release of $\mathrm{Cl}^{-}$ through a pathway following the potential energy surface of the ion-pair state, analogous to that followed by $\mathrm{CH}_{3} \mathrm{Cl}$. The ion-pair state is populated within the sub-picosecond scale (about $150 \mathrm{fs}$ ) and its yield depends on the excitation energy. An increase in the excitation window from $10.0 \pm 0.25 \mathrm{eV}$ to $11.2 \pm 0.25 \mathrm{eV}$ (reaching the $\sigma 4 \mathrm{p}_{\sigma}$ state) leads to an increase from 4 to $15 \%$ in the $\mathrm{Cl}^{-}$yield.

At the highest computational level (MR-CISD+Q), the vertical excitation energy of the $\sigma 4 p_{\sigma}$ state is $12.0 \mathrm{eV}(103.3 \mathrm{~nm})$. As the transition to this state is the one with the largest $f$ value, to facilitate $\mathrm{Cl}^{-}$release from the HCFC-133a molecule, we suggest studying its photodissociation at a wavelength close to $103 \mathrm{~nm}$.

Finally, $\mathrm{Cl}^{-}$release can in principle take place in related compounds, as some chloro-carbonyl compounds, ${ }^{64-67}$ as long as: (i) the $\mathrm{R}_{-} \mathrm{CH}_{2}$ and $\mathrm{Cl}$ open-shell doublet radicals are present not very far from each other, during photodissociation of the parent compound; and (ii) the excitation energy is high enough to achieve the ion pair channel.

\section{ASSOCIATED CONTENT}

\section{Supporting Information}

The Supporting Information is available free of charge on the ACS Publications website. Potential energy curves; Cartesian coordinates; Displacement vectors of the normal modes; Molecular orbitals; Discussion on the basis sets choice.

\section{AUTHOR INFORMATION}

\section{Corresponding authors}

*E-mail: mario.barbatti@univ-amu.fr; website: www.barbatti.org

*E-mail: $\underline{\text { silmar@quimica.ufpb.br or silmar.monte@uol.com.br }}$

\section{ORCID}


Gessenildo P. Rodrigues: 0000-0002-1166-9231

Thayana Maria Lopes de Lima: 0000-0001-8648-2108

Railton B. de Andrade: 0000-0001-5804-4186

Elizete Ventura: 0000-0002-1015-7824

Silmar A. do Monte: 0000-0002-5878-1984

Mario Barbatti: 0000-0001-9336-6607

\section{Acknowledgment}

M.B. thanks the support of the Excellence Initiative of Aix-Marseille University (A*MIDEX) and the project Equip@Meso (ANR-10-EQPX-29-01), both funded by the French Government "Investissements d'Avenir" program m. M.B. also acknowledges funding the WSPLIT project (ANR-17-CE05-0005-01). E.V. thanks the support of the Brazilian agency CNPq (Grant number 309785/2015-4). The remaining authors are grateful of the Brazilian agencies CAPES and FINEP for financial support. They are also thankful for the computational facilities at the CESUP/UFRGS supercomputing center.

\section{Notes}

The authors declare no competing financial interest.

\section{References}

1. Seinfeld, J. H.; Pandis, S. N. Atmospheric Chemistry and Physics: From Air Pollution to Climate Change. Willey: 2016.

2. Society, A. C. Which Gases Are Greenhouse Gases? ACS Climate Science Toolkit | Greenhouse Gases. https://www.acs.org/content/acs/en/climatescience/greenhousegases/whichgases.html.

3. Kyoto Protocol to the United Nations Framework Convention on Climate Change; Kyoto, 1997.

4. $\quad$ Downie, D. L., Stratospheric Ozone Depletion. Routledge: New York, 2013.

5. Downie, D. L. The Vienna Convention, Montreal Protocol and Global Policy to Protect Stratospheric Ozone. Taylor \& Francis: Oxford, U.K., 2012.

6. Andersen, S. O.; Sarma, K. M.; Taddonio, K. N. Technology Transfer for the Ozone Layer: Lessons for Climate Change. Earthscan Press: London, 2007.

7. Andersen, S. O.; Sarma, K. M. Protecting the Ozone Layer: the United Nations History. Earthscan Press: London, 2002. 
8. Report of the Fourth Meeting of the Parties to the Montreal Protocol on Substances that Deplete the Ozone Layer; United Nations Environment Panel: New York, 1992.

9. Miller, M.; Batchelor, T. Information Paper on Feedstock Uses of OzoneDepleting

Substances. [http://ec.europa.eu/clima/policies/ozone/research/docs/feedstock_en.pdf]. 2012, 72.

10. Manzer, L. E. The CFC-Ozone Issue: Progress on the Development of Alternatives to CFCs. Science 1990, 249, 31-35.

11. Laube, J. C.; Newland, M. J.; Hogan, C.; Brenninkmeijer, C. A. M.; Fraser, P. J.; Martinerie, P.; Oram, D. E.; Reeves, C. E.; Röckmann, T.; Schwander, J.; et al. Newly Detected Ozone-Depleting Substances in the Atmosphere. Nat. Geosci. 2014, 7, 266-269.

12. McGillen, M. R.; Bernard, F.; Fleming, E. L.; Burkholder, J. B. HCFC-133a $\left(\mathrm{CF}_{3} \mathrm{CH}_{2} \mathrm{Cl}\right): \mathrm{OH}$ Rate Coefficient, $\mathrm{UV}$ and Infrared Absorption Spectra, and Atmospheric Implications. Geophys. Res. Lett. 2015, 42, 6098-6105.

13. Setser, D. W.; Lee, T. S.; Danen, W. C. Infrared Multiphoton Absorption and Reaction of 2-Chloro-1,1,1 trifluoroethane. J. Phys.Chem. 1985, 89, 5799-5805.

14. Rakestraw, D. J.; Holmes, B. E. Unimolecular Rate Constants for Chemically Activated 1,1,1-Trifluoro-2-chloroethane: A Competitive Three-Channel System. $J$. Phys. Chem. 1991, 95, 3968-3975.

15. Enstice, E. C.; Duncan, J. R.; Setser, D. W.; Holmes, B. E. Unimolecular Reactions in the $\mathrm{CF}_{3} \mathrm{CH}_{2} \mathrm{Cl} \leftrightarrow \mathrm{CF}_{2} \mathrm{ClCH}_{2} \mathrm{~F}$ System: Isomerization by Interchange of $\mathrm{Cl}$ and F Atoms. J. Phys. Chem. A. 2010, 115, 1054-1072.

16. Wang, L.; Zhao, Y.; Zhang, J.; Dai, Y.; Zhang, J. Dual-Level Direct Dynamics Studies on the Hydrogen Abstraction Reactions of Fluorine Atoms with $\mathrm{CF}_{3} \mathrm{CH}_{2} \mathrm{X}(\mathrm{X}=$ F, Cl). Theor. Chem. Acc. 2011, 128, 183-199.

17. Zhao, Y.; He, H.; Zhang, J.; Wang, L. Direct Dynamics Study of the Hydrogen Abstraction Reaction of $\mathrm{CF}_{3} \mathrm{CH}_{2} \mathrm{Cl}+\mathrm{Cl} \rightarrow \mathrm{CF}_{3} \mathrm{CHCl}+\mathrm{HCl}$. Int. J. Chem. Kinet. 2012, 44, 661-667.

18. Ichimura, T.; Kirk, A. W.; Tschuikow-Roux, E. Primary Processes in the 147and 123.6-nm Photolyses of 1,1,1-Trifluoro-2-chloroethane. J. Phys. Chem. 1977, 81, 1153-1156.

19. Rodrigues, G. P.; Lucena Jr., J. R.; Ventura, E.; do Monte, S. A.; Reva, I.; Fausto, R. Matrix Isolation Infrared Spectroscopic and Theoretical Study of 1,1,1trifluoro-2-chloroethane (HCFC-133a). J. Chem. Phys. 2013, 139, 204302-204310.

20. Rodrigues, G. P.; Ventura, E.; do Monte, S. A.; Barbatti, M. Photochemical Deactivation Process of HCFC-133a $\left(\mathrm{C}_{2} \mathrm{H}_{2} \mathrm{~F}_{3} \mathrm{Cl}\right)$ : A Nonadiabatic Dynamics Study. $J$. Phys. Chem. A. 2014, 118, 12041-12049.

21. Simpson, M. J.; Tuckett, R. P. Vacuum-UV Negative Photoion Spectroscopy of Gas-Phase Polyatomic Molecules. Int. Rev. Phys. Chem. 2011, 30, 197-273.

22. Rogers, N. J.; Simpson, M. J.; Tuckett, R. P.; Dunn, K. F.; Latimer, C. J. Vacuum-UV Negative Photoion Spectroscopy of $\mathrm{CH}_{3} \mathrm{~F}, \mathrm{CH}_{3} \mathrm{Cl}$ and $\mathrm{CH}_{3} \mathrm{Br}$. Phys. Chem. Chem. Phys. 2010, 12, 10971-10980. 
23. De Medeiros, V. C.; De Andrade, R. B.; Leitão, E. F. V.; Ventura, E.; Bauerfeldt, G. F.; Barbatti, M.; Do Monte, S. A. Photochemistry of $\mathrm{CH}_{3} \mathrm{Cl}$ : Dissociation and $\mathrm{CH} \cdots \mathrm{Cl}$ Hydrogen Bond Formation. J. Am. Chem. Soc. 2016, 138, 272-280.

24. Crespo-Otero, R.; Barbatti, M. Recent Advances and Perspectives on Nonadiabatics Mixed Quantum-Classic Dynamics. Chem. Rev. 2018, 118, 7026-7068.

25. Kendall, R. A.; Dunning, T. H., Jr.; Harrison, R. J. Electron Affinities of the FirstRow Atoms Revisited. Systematic Basis Sets and Wave Functions. J. Chem. Phys. 1992, 96, 6796-6807.

26. De Medeiros, V. C.; Ventura, E.; do Monte, S. A. CASSCF and MR-CISD Study of the $\mathrm{n}-4 \mathrm{~s}$ and $\mathrm{n}-4$ pe Rydberg States of the $\mathrm{CF}_{3} \mathrm{Cl}$. Chem. Phys. Lett. 2012, 546, 30-33.

27. Lucena, J. R., Jr.; Ventura, E.; do Monte, S. A.; Araújo, R. C. M. U.; Ramos, M. N.; Fausto, R. Dissociation of Ground and n $\sigma^{*}$ States of $\mathrm{CF}_{3} \mathrm{Cl}$ Using Multireference Configuration Interaction with Singles and Doubles and with Multireference Average Quadratic Coupled Cluster Extensivity Corrections. . J. Chem. Phys. 2007, 127, 164320164330.

28. Bunge, A. Electronic Wavefunctions for Atoms III. Partition of Degenerate Spaces and Ground State of C. J. Chem. Phys. 1970, 53, 20-28.

29. Langhoff, S. R.; Davidson, E. R. Configuration Interaction Calculations on Nitrogen Molecule. Int. J. Quantum Chem. 1974, 8, 61-72.

30. Bruna, P. J.; Peyerimhoff, S. D.; Buenker, R. J. The Ground-State of the $\mathrm{CN}^{+}$Ion - a Multi-Reference CI Study. Chem. Phys. Lett. 1980, 72, 278-284.

31. De Medeiros, V. C.; De Andrade, R. B.; Rodrigues, G. P.; Bauerfeldt, G. F.; Ventura, E.; Barbatti, M.; Do Monte, S. A. Photochemistry of $\mathrm{CF}_{3} \mathrm{Cl}$ : Quenching of Charged Fragments Is Caused by Nonadiabatic Effects. J. Chem. Theory Comput. 2018, $14,4844-4855$.

32. Gronert, S.; Keefe, J. R. Calculated Stabilities and Structures for Carbocations and Singlet Carbenes Bearing Electron-Withdrawing Groups. J. Phys. Org. Chem. 2013, 26, 1023-1031.

33. Tully, J. C. Nonadiabatic Molecular Dynamics. Int. J. Quantum Chem.: Quantum Chem. Simposium 1991, 25, 299-309.

34. Granucci, G.; Persico, M. Critical Appraisal of the Fewest Switches Algorithm for Surface Hopping. J. Chem. Phys. 2007, 126, 134114.

35. Barbatti, M.; Pittner, J.; Pederzoli, M.; Werner, U.; Mitrić, R.; BonačićKoutecký, V.; Lischka, H. Non-Adiabatic Dynamics of Pyrrole: Dependence of Deactivation Mechanisms on the Excitation Energy. Chem. Phys. 2010, 375, 26-34.

36. Chai, J.-D.; Head-Gordon, M. Long-Range Corrected Hybrid Density Functionals with Damped Atom-Atom Dispersion Corrections. Phys. Chem. Chem. Phys. 2008, 10, 6615-6620.

37. Plasser, F.; Crespo-Otero, R.; Pederzoli, M.; Pittner, J.; Lischka, H.; Barbatti, M. Surface Hopping Dynamics with Correlated Single-Reference Methods: 9H-Adenine as a Case Study. J. Chem. Theory Comput. 2014, 10, 1395-1405.

38. Shepard, R.; Lischka, H.; Szalay, P. G.; Kovar, T.; Ernzerhof, M. A General Multireference Configuration-Interaction Gradient Program. J. Chem. Phys. 1992, 96, 2085-2098. 
39. Shepard, R. The Analytic Gradient Method for Configuration Interaction Wave Functions. In Modern Electronic Structure Theory; Yarkony, D. R., Ed.; World Scientific: Singapore 1995, 1, 245.

40. Shepard, R. Geometrical Energy Derivative Evaluation with MRCI Wave Functions. Int. J. Quantum Chem. 1987, 31, 33-34.

41. Lischka, H.; Dallos, M.; Shepard, R. Analytic MRCI Gradient for Excited States: Formalism and Application to the $n-\pi^{*}$ Valence and $n-(3 s, 3 p)$ Rydberg States of Formaldehyde. Mol. Phys. 2002, 100, 1647-1658.

42. Frisch, M. J.; Trucks, G. W.; Schlegel, H. B.; Scuseria, G. E.; Robb, M. A.; Cheeseman, J. R.; Scalmani, G.; Barone, V.; Mennucci, B.; Petersson, G. A.; et al, Gaussian 09, Revision D.01; Gaussian, Inc.: Wallingford, CT, 2013.

43. Shepard, R.; Shavitt, I.; Pitzer, R. M.; Comeau, D. C.; Pepper, M.; Lischka, H.; Szalay, P. G.; Ahlrichs, R.; Brown, F. B.; Zhao, J. A Progress Report on the Status of the COLUMBUS MRCI Program System. Int. J. Quantum Chem. 1988, 34, 149-165.

44. Lischka, H.; Shepard, R.; Shavitt, I.; Pitzer, R. M.; Dallos, M.; Müller, T.; Szalay, P. G.; Brown, F. B.; Ahlrichs, R.; Böhm, H. J.; et al. COLUMBUS, an Ab Initio Electronic Structure Program, Release 7.0. www.univie.ac.at/columbus (accessed September 4, 2018).

45. Lischka, H.; Shepard, R.; Pitzer, R. M.; Shavitt, I.; Dallos, M.; Müller, T.; Szalay, P. G.; Seth, M.; Kedziora, G. S.; Yabushita, S.; et al. New High-Level Multireference Methods in the Quantum-Chemistry Program System COLUMBUS: Analytic MR-CISD and MR-AQCC Gradients and MR-AQCC-LRT for Excited States, GUGA Spin-Orbit CI, and Parallel CI Density. Phys. Chem. Chem. Phys. 2001, 3, 664673.

46. Lischka, H.; Shepard, R.; Brown, F. B.; Shavitt, I. New Implementation of the Graphical Unitary-Group Approach for Multi-Reference Direct ConfigurationInteraction Calculations. Int. J. Quantum Chem. 1981, 20, 91-100.

47. Helgaker, T.; Jensen, H. J. A.; Jørgensen, P.; Olsen, J.; Ruud, K.; Ågren, H.; Andersen, T.; Bak, K. L.; Bakken, V.; Christiansen, O.; et al. DALTON, an Ab Initio Electronic Structure Program, Release 1.0. 1997.

48. Barbatti, M.; Ruckenbauer, M.; Plasser, F.; Pittner, J.; Granucci, G.; Persico, M.; Lischka, H. Newton-X: A Surface-Hopping Program for Nonadiabatic Molecular Dynamics. WIREs: Comp. Mol. Sci. 2014, 4, 26-33.

49. Barbatti, M.; Granucci, G.; Ruckenbauer, M.; Plasser, F.; Crespo-Otero, R.; Pittner, J.; Persico, M.; Lischka, H. NEWTON-X: A package for Newtonian Dynamics Close to the Crossing Seam. Available via the Internet at www.newtonx.org. 2018.

50. Rodrigues, G. P.; Lucena, J., Jr.; Ventura, E.; do Monte, S. A. Accurate Calculation of the Ionization Energies of the Chlorine Lone Pairs in 1,1,1-trifluoro-2chloroethane (HCFC-133a). J. Mol. Model. 2014, 20, 2393-2400.

51. Karlsson, L.; Jadrny, R.; Mattsson, L.; Chau, F. T.; Siegbahn, K. Vibrational and Vibronic Structure in the Valence Electron Spectra of $\mathrm{CH}_{3} \mathrm{X}$ Molecules (X=F, CI, Br, I, OH). Phys. Scr. 1977, 16, 225-234.

52. Fisher, I. P.; Homer, J. B.; Lossing, F. P. Free Radicals by Mass Spectrometry. XXXIII. Ionization Potentials of $\mathrm{CF}_{2}, \mathrm{CF}_{3} \mathrm{CF}_{2}, \mathrm{CF}_{3} \mathrm{CH}_{2}, \mathrm{n}-\mathrm{C}_{3} \mathrm{~F}_{7}$ and i- $\mathrm{C}_{3} \mathrm{~F}_{7}$ Radicals. $J$. Am. Chem. Soc. 1965, 87, 957-960. 
53. Cai, J.; Sessler, J. L. Neutral CH and Cationic CH Donor Groups as Anion Receptors. Chem. Soc. Rev. 2014, 43, 6198-6213.

54. Matthews, R. P.; Ashworth, C.; Welton, T.; Hunt, P. A. The Impact of Anion Electronic Structure: Similarities and Differences in Imidazolium Based Ionic Liquids. $J$. Phys.: Condens. Matter 2014, 26, 284112.

55. Lungwitz, R.; Spange, S. A Hydrogen Bond Accepting (HBA) Scale for Anions, Including Room Temperature Ionic Liquids. New J. Chem. 2008, 32, 392-394.

56. Izgorodina, E. I.; MacFarlane, D. R. Nature of Hydrogen Bonding in Charged Hydrogen-Bonded Complexes and Imidazolium-Based Ionic Liquids. J. Phys. Chem. B 2011, 115, 14659-14667.

57. Hunt, P. A.; Kirchner, B.; Welton, T. Characterising the Electronic Structure of Ionic Liquids: An Examination of the 1-Butyl-3-Methylimidazolium Chloride Ion Pair. Chem. Eur. J. 2006, 12, 6762-6775.

58. Hunt, P. A.; Gould, R.; Kirchner, B. The Structure of Imidazolium-Based Ionic Liquids: Insights from Ion-Pair Interactions. Aust. J. Chem. 2007, 60, 9-14.

59. Hunt, P. A.; Gould, I. R. Structural Characterization of the 1-Butyl-3Methylimidazolium Chloride Ion Pair Using Ab Initio Methods. J. Phys. Chem. A. 2006, 110, 2269-2282.

60. Dymek, C. J.; Grossie, D. A.; Fratini, A. V.; Adams, W. W. Evidence for the Presence of Hydrogen-Bonded Ion-Ion Interactions in the Molten Salt Precursor, 1methyl-3-ethylimidazolium chloride. J. Mol. Struct. 1989, 213, 25-34.

61. Kludt, J. R.; Kwong, G. Y. W.; McDonald, R. L. Far Infrared Spectra of Tertiary Ammonium Salts. J. Phys. Chem. 1972, 76, 339-342.

62. Silverstein, R. M.; Webster, F. X.; Kiemle, D. J. Spectrometric Identification of Organic Compounds. 7th ed.; John Wiley \& Sons: NJ, USA, 2005.

63. Jonas, D. M. Two-Dimensional Femtosecond Spectroscopy. Annu. Rev. Phys. Chem. 2003, 54, 425-463.

64. Adams, J. D.; Scrape, P. G.; Li, S.; Li, S.-H.; Butler, L. J. Primary Product Branching in the Photodissociation of Chloroacethaldehyde at $157 \mathrm{~nm}$. J. Phys. Chem. A. 2017, 121, 6732-6741.

65. Cui, G.; Sun, Z.; Fang, W. Adiabatic and Nonadiabatic Bond Cleavages in Norrish Type I Reaction. J. Phys. Chem. A. 2011, 115, 10146 - 10153.

66. Cui, G.-L.; Li, Q.-S.; Zhang, F.; Fang, W.-H.; Yu, J.-G. Combined CASSCF and MR-CI Study on Photoinduced Dissociation and Isomerization of Acryloyl Chloride. J. Phys. Chem. A. 2006, 110, 11839 - 11846.

67. Lam, C.-S.; Adams, J. D.; Butler, L. J. The Onset of H + Ketene Products from Vinoxy Radicals Prepared by Photodissociation of Chloroacetaldehyde at $157 \mathrm{~nm}$. $J$. Phys. Chem. A. 2016, 120, 2521 - 2536. 


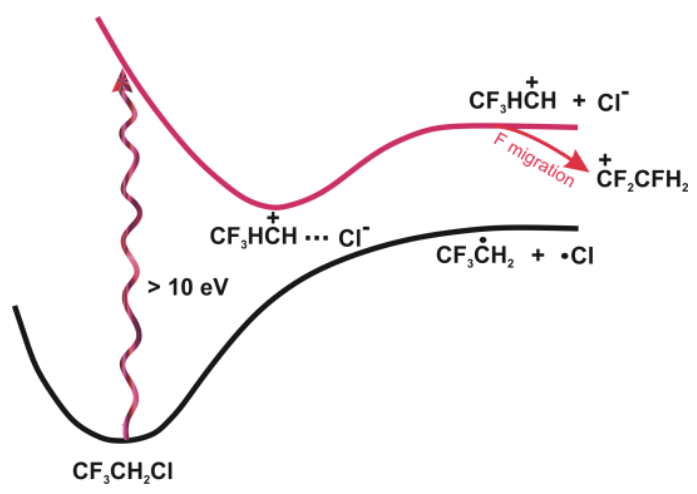

